\title{
Gesture recognition vehicle using PIC microcontroller
}

\author{
K.Selvakumar, R.Palanisamy, M.Arun Noyal Doss, P.Gopi, A.Esakkipandi, L.Mathivadhanam, \\ T.Abul Kalam Asath \\ Department of EEE, SRM Institute of Science and Technology, India
}

\begin{tabular}{l} 
Article Info \\
\hline Article history: \\
Received Jul 8, 2019 \\
Revised Nov 9, 2020 \\
Accepted Jan 21, 2020 \\
\hline
\end{tabular}

\section{Keywords:}

Gesture Recognition Vehicle

PIC microcontroller

Receiver

Transmitter

\begin{abstract}
In this paper we introduce a hand controlled robotic vehicle. Hand control robotic vehicle consists of a transmitter module and a receiver module. The transmitter will be placed on a hand glove and the receiver will be placed on the motor drive along with PIC microcontroller and motor driver IC. The RF transmitter sends commands to the IC which then forwards the commands to RF receiver. The RF receiver then sends the commands to PIC microcontroller on the vehicle which processes the commands so that the vehicle moves in the specified desired direction. It is having proposed utility in field ofconstruction, hazardous waste disposal and field survey near borders etc. This project is developed as a travel buddy and industrial uses. Having future scope of advanced robotics that are designed and can be easily controlled using hand gesture only.
\end{abstract}

Copyright $\odot 2020$ Institute of Advanced Engineering and Science. All rights reserved.

\section{Corresponding Author:}

R. Palanisamy, Department of EEE, SRM Institute of Science and Technology, India.

Email: krspalani@gmail.com

\section{INTRODUCTION}

In current scenario, robots are playing an important role in real world. Keeping this in mind, the proposed system consists of a basic prototype of hand controlled robotic vehicle [1]. This project consists of a DC motor, PIC microcontroller, accelerometer and RF module transmitter receiver [2-5].

The project uses a DC Motor instead of a Stepper motor since resonant effect is often seen at low speeds in stepper motors [6-8]. Also, there is decrease in torque with increase in speed which makes it slow if a high torque is needed [9, 10]. A servo motor has high torque and accurate rotation in a limited angle which makes it a high-performance alternative to stepper motor and dc motor $[11,12]$. But the complication of PWM (pulse width modulation) restricts it from being used in this project. On the other hand a dc motor meets our requirement of speed-torque characteristics of required RPM [13, 14].

PIC 16f377A microcontroller has been used in the project because of its easy programming and interfacing properties with other peripherals $[15,16]$. Microcontroller from 8051 family cannot interface high power devices without any extra circuitry support and also it performs limited number of executions simultaneously which is the reason this family has been avoided in this project $[17,18]$.

Based on this project, the real time applications ranges from its use in military for controlling robotic instruments, in industries for controlling lifts and trollies, in constructional sites to even medical purposes [19, 20].

\section{PROPOSED SYSTEM}

The project consists of two parts viz. the Transmitter Module, which is the circuit on the hand, and the Receiver Module, which is a battery operated vehicle following four quadrant operation of motor. 


\subsection{The transmitter module}

The gestures are done by hand and this is recognized by assistance computing gadget called accelerometer. The accelerometer reads the XYZ co-ordinates made by our hand and send it to the microcontroller. The microcontroller is programmed on five functions-front, back, left, right and stop. Taking the hand towards our body indicates back, taking it forward away from body indicates front, tilting it towards left side indicates left and tilting towards right side indicates right. No movement of the hand will indicate it to stop. Any of the above mentioned movement is done which is checked by the microcontroller to send the required values of co-ordinates to the encoder in the form of 4 bit code. The encoder passes the specifics to the RF Transmitter. This data is thus sensed by the receiver and the function continues in the Receiver Module as shown in Figure 1.

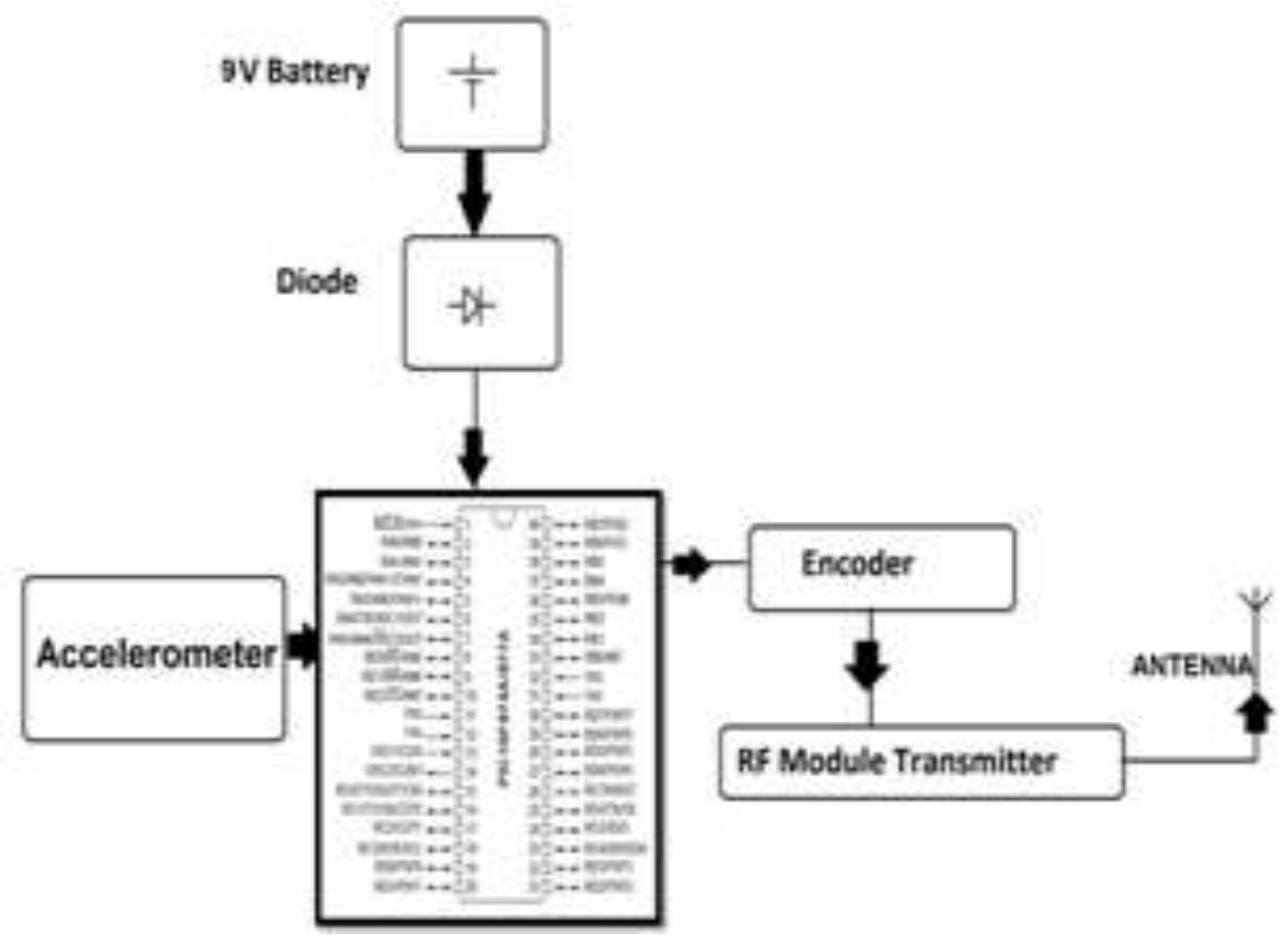

Figure 1. Block diagram of transmitter module

This module consists of the following

1. PIC 16f877A Microcontroller

2. Accelerometer

3. Encoder

4. RF Transmitter

5. Power Supply

\subsection{The receiver module}

The data received from the RF Transmitter from the Transmitter Module is sensed by the RF Receiver. This data is then sent to the Decoder. The decoder here is used to change the serial data into parallel data. The changed data is further sent to the microcontroller on this module. This microcontroller is programmed such that it follows the four quadrant operation of motor i.e. motor turning clockwise, anticlockwise, forwards ad backwards. Clockwise rotation is meant for turning the vehicle towards right, anticlockwise is for left, forward is for moving the vehicle towards front and backwards is for back. Stop is used as break. This, after recognizing the given instructions, is sent to the Motor Driver IC. This IC receives signal from microcontroller and sends it to the motor. The motor then works accordingly making the vehicle work according to the hand gesture made by the operator from the transmitter module as shown in Figure 2. 


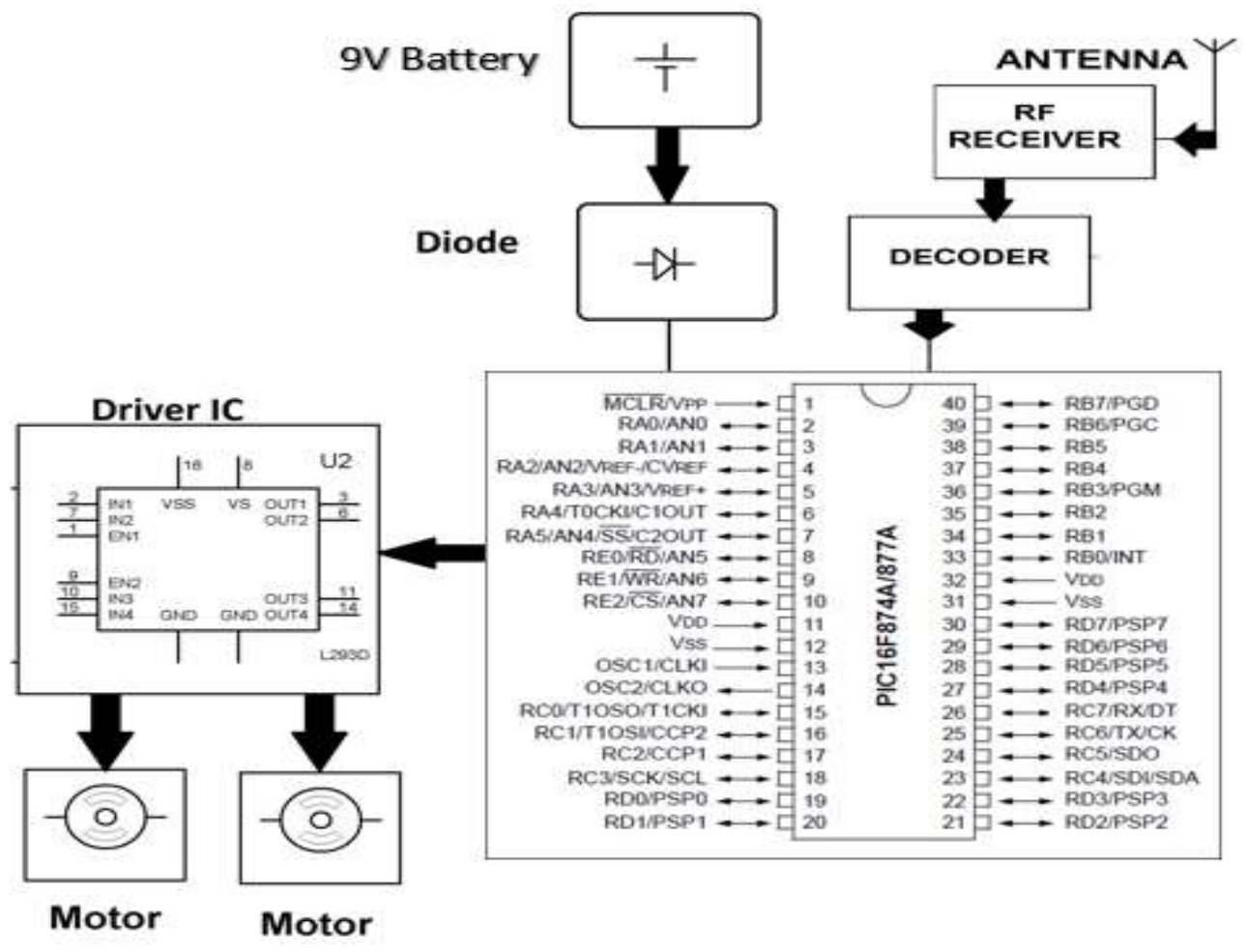

Figure 2. Schematic diagram of receiver module

This module constitutes the following:

1. DC Motor

2. Motor Driver IC- L293D

3. PIC 16f877A Microcontroller

4. Decoder

5. RF Receiver

6. Power Supply

\section{DC MOTOR}

DC Motor is a specific that converts electrical energy into mechanical energy. It works on the concept that when a current carrying conductor cuts magnetic flux which is produced by field windings a mechanical force is applied on it. The direction of this mechanical force is given by Fleming's left hand rule and is given by F=BIL. In other words a dc motor works on the forces produced by the magnetic fields [21-25].

\subsection{Anatomy of a DC Motor (Figure 3)}

1) Stator-It is the stationary part of motor, it is responsible for generating the magnetic field that drives the rotating part. It carries the fiield winding.

2) Rotor-It is the rotating part of motor, rotor cuts the magnetic flux and moves in the respective direction. It carries the armature winding.

3) Armature Winding-It is the current carrying winding which rotates on interaction with the magnetic field. It is the load carrying member which is mounted on the rotor.

4) Field Winding-It is the excitation system, which generates the magnetic field. Excitation system may consist of a magnet or electromagnet.

5) Commutator-The electrical power is fed to rotor through commutator. It rotates along with the rotor to make sure current is in correct direction in armature coil.

6) Brushes-Brushes are used to send current into the armature winding.

7) Poles-Field winding is divided into sets, each set represents the north and south pole of a magnet. The number of poles determines the rating of motor. 


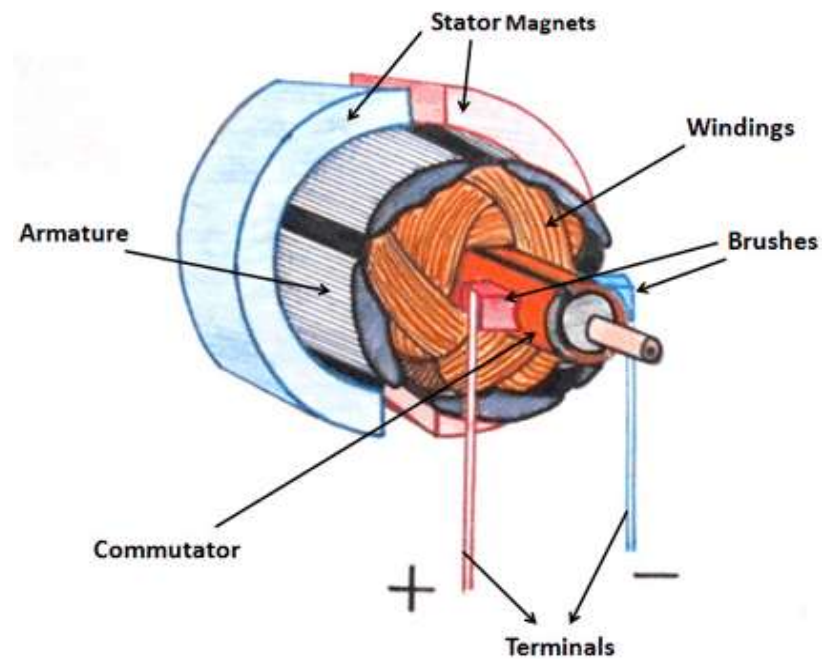

Figure 3. Anatomy of DC Motor

\subsection{Categorisation}

DC Motor is mainly categorised as brushed and brushless motor

1. Figure 4 show Brushed-Brushed dc motor are the ones that involves carbon brushes, spring and commutator. Current is delivered to the windings through commutator contacts. Brushed dc motor has a advantage that it has a simplified circuit and can be used in places where cost and simplicity of circuit is a matter of concern. However the brushed dc motor involves replacement of brushes and spring, and also requires cleaning of commutator. And the switching action of commutators creates a lot of noise [26, 27].

2. Fugure 5 show Brushless-Brushless motor excludes the current carrying commutator. The timing and phase of current in rotor coil is controlled by sensing the rotor position using Hall effect sensors. By controlling phase and timing of the rotor current, torque and speed of the motor can be optimised. In brushless motor windings are on the stationary part. Brushless motors provide greater efficiency over brushed motor. It is less noisy as it does not involve commutators.

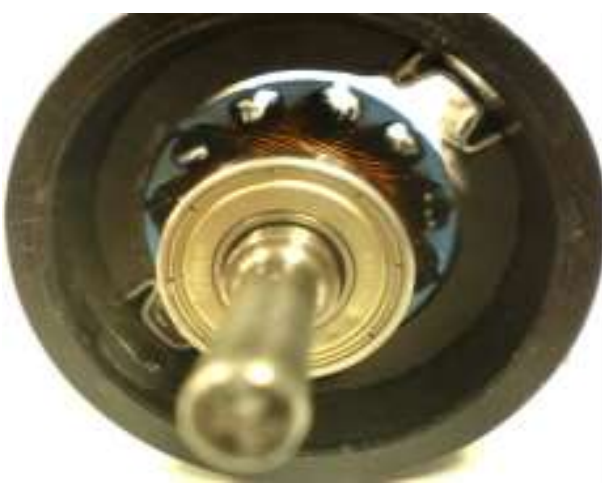

Figure 4. Brushed of DC motor

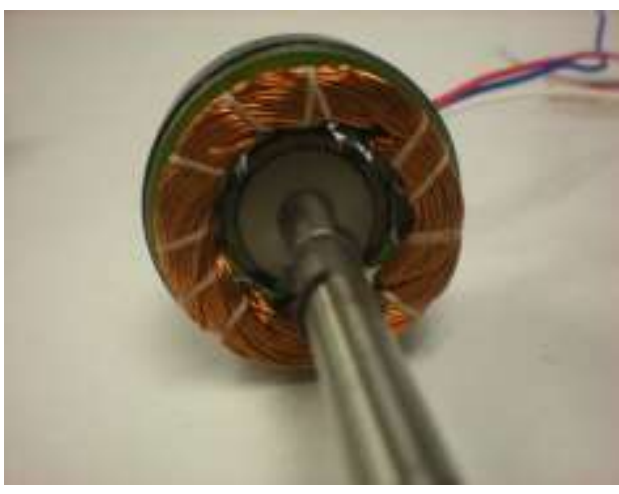

Figure 5. Brushless DC motor

\subsection{Motor specifications}

Motor used in our project is a brushed dc motor whose specification are:

1. Operating Voltage-3-12V

2. Speed-100-130 RPM

3. Load Current-70 mA (250 mA max at $3 \mathrm{~A})$

4. Weight-29 gms

5. Dimensions- $67 * 37 * 22$ millimetre

6. Gear Ratio-1:48 


\subsection{Driver IC}

Motor Driver IC is used for providing the required voltage and current to the motors, which is not possible with the microcontroller as it works at voltage and current. The driver IC used here is a L293D IC, it receives signal from pic microcontroller and sends signal to the motors. The circuit for low current rated motor is H-Bridge, L293D uses two H-Bridge. The function of H-Bridge is to switch direction of motors clockwise and anticlockwise, by changing voltage polarity. This change in motor direction helps vehicle to move forward, backward, left and right. The L293D consists of two voltage pins, supply voltage is provided in one pin and the other is used to provide voltage to motors.

\subsection{Specifications}

- Voltage Rating-4.5 to $36 \mathrm{~V}$

- Output Current per driver-600mA

- Pulsed current per driver-1.2A

- Separate input-logic supply

- Thermal shutdown

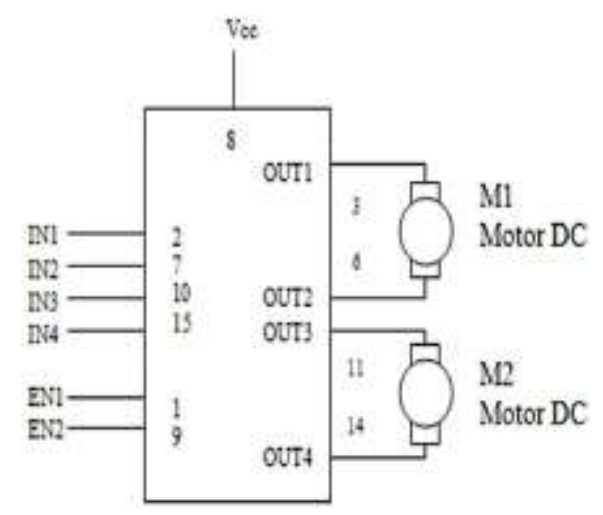

Figure 6. Connections of DC Motor

\section{MICROCONTROLLER PIC16f877A}

This is very convenient to use. The script for this microcontroller is simple and easy compared to other microcontrollers. Its main advantage is that it uses Flash memory so erase-write functions can be done many times. PIC 16f877A is used in many pic microcontroller applications and electronic applications. EEPROM is a feature of the microcontroller which makes it store information permanently. Pin Configuration and Description as shown in Figure 7:

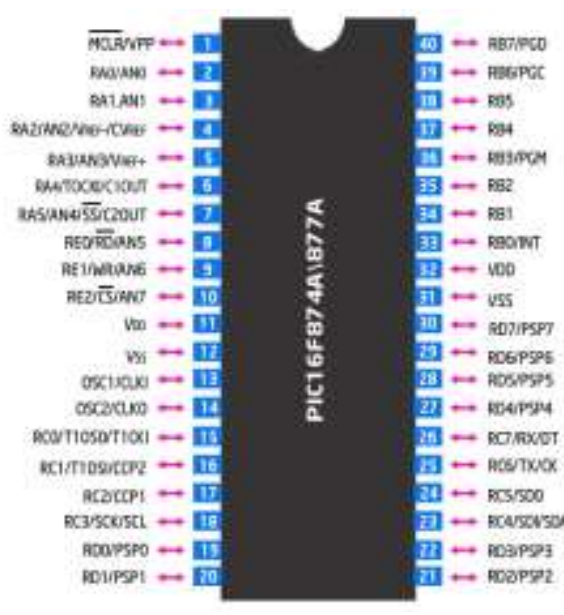

Figure 7. Pin Diagram- 16F877A 
There are 40 pins for pic 16f877A. It comprises total two 8 bit timer and one 16 bit timer. It has total 5 port (PortA, PortB, PortC, PortD and PortE).

PIN 1- MCLR:

It is the master clear and an active low pin which means that a constant voltage of $5 \mathrm{~V}$ must be continuously is given to the pin. If $0 \mathrm{~V}$ is given then the microcontroller is reset. By resetting, it will bring back to the first line of the program.

PIN 2 to PIN 7- PORTA:

Port A consists of 6 pins. All are input- output pins and are bidirectional. These pins act as analog input.

Pin 4 act as an input for analog signals. It can also be used for negative reference voltage.

Pin 5 can act as analog input 3 or a positive reference voltage can be applied to this pin.

Pin6 can act as a timer input pin.

Pin7 can act as analog input4. The controller uses synchronous serial port which this pin acts as slave for it.

PIN 8 to PIN 10- PORT E:

All are input- output pins and are bidirectional. It can act as a read control pin during active low.

PIN 11 and PIN32:

These are pins where positive supply of $5 \mathrm{~V}$ is given for the input-output pins.

PIN 12 and PIN 32:

These are the pins where ground reference with zero potential is given for the input-output pins.

PIN 13 and PIN 14:

These pins are defined as the oscillator input and output pin.

PIN 16-PIN16 and PIN 23-PIN28: PORT C:

These pins are also used for Serial Communication.

PIN 19, 20, 21, 22, 27, 28, 29, and 30-PORT D:

All these are input-output bidirectional pins.

PIN 33 to 40:

The $0^{\text {th }}$ pin of PORT B is the external input pin and the $6^{\text {th }}$ and $7^{\text {th }}$ are the in-circuit debugger pins.

PIC16F877A Features:

- Operating voltage: $2-5.5 \mathrm{v}$

- External oscillator: Upto $20 \mathrm{MHz}$

- Program memory: Flash Memory

- Program memory size: $14 \mathrm{~kb}$

- CPU Speed: 5 Million Instructions per seconds.

- RAM size: 368 bytes

- Data EEPROM: 256 byte

\section{ACCELEROMETER (Figure 8-9)}

An accelerometer is a measuring device which specifically computes the acceleration of any moving object. It is a 3-axis measurement device with $+-3 \mathrm{~g}$ as the range. When we tilt the object, it determines the static acceleration of gravity. Poly silicon surface and signal conditioning circuits are used in this component which counts the acceleration. The output obtained is in the form of analog signals. The result obtained by this is in the form of motion or vibration. When we tilt in $\mathrm{X}, \mathrm{Y}$ or $\mathrm{Z}$ direction the sensor senses it and gives the corresponding output. The bandwidth range for an ADXL335 accelerometer is from $0.500 \mathrm{~Hz}$ to $1550 \mathrm{~Hz}$ for $\mathrm{X}$ and $\mathrm{Y}$ axis. Accelerometers being lo power devices should have current range in between milliamps or micro amps. The voltage ranges between $3 \mathrm{~V}$ to $6 \mathrm{~V}$ dc supply.

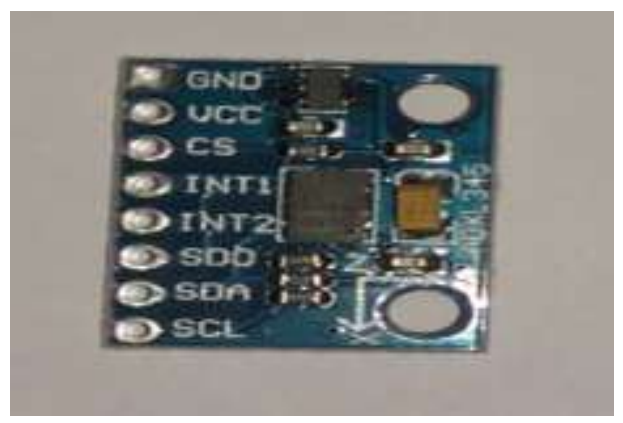

Figure 8. Pin diagram-accelerometer 
PIN 1: VCC input pin used to give a positive supply of $5 \mathrm{~V}$ with regulated power.

PIN 2: This pin is connected to the ground for the sake of biasing.

PIN 3: $\mathrm{X}$ channel output pin will receive the data sent in the $\mathrm{x}$ axis.

PIN4: Y channel output pin will receive the data sent in y axis.

PIN 5: $\mathrm{Z}$ channel output pin will receive the data sent in $\mathrm{Z}$ axis.

PIN 6: ST pin is used to calibrate the sensitivity of the accelerometer.

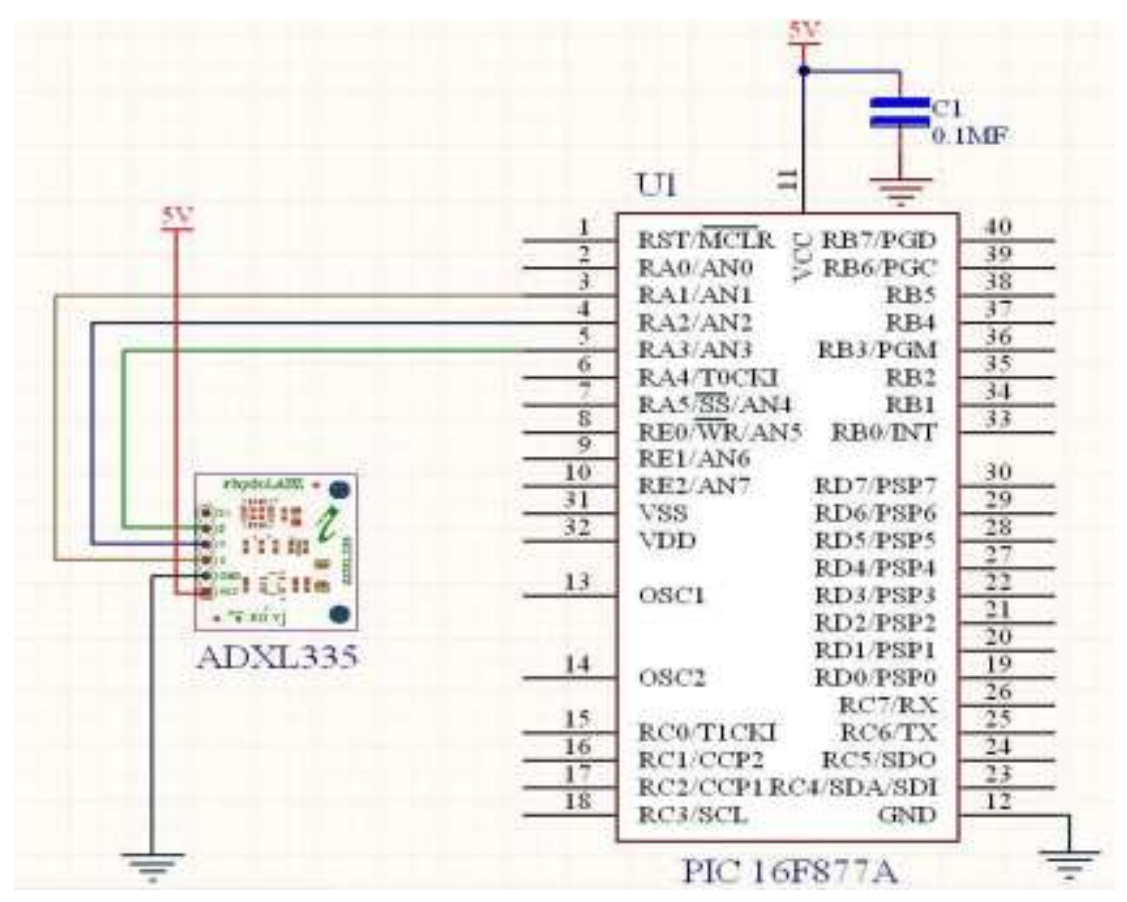

Figure 9. Connections of accelerometer

For a gesture controlled robot the accelerometer plays a major role in it. The accelerometer is connected to the microcontroller as shown in Figure. In this the $\mathrm{X}, \mathrm{Y}, \mathrm{Z}$ pins are connected to port $\mathrm{A}$ of the microcontroller. The $\mathrm{X}$ is connected to pin RA1, $\mathrm{Y}$ is to pin RA2 and $\mathrm{Z}$ to pin RA3.

When we move our hand the accelerometer senses it and then detects the axis and accordingly sends the output.

For a gesture controlled robot only $\mathrm{X}$ and $\mathrm{Y}$ axis are needed. After giving hand gestures the accelerometer detects it and sends the signal to the microcontroller. The required values of co-ordinates are then sending to the encoder in the form of 4 bit code. The encoder passes the specifics to the RF Transmitter. This data is thus sensed by the receiver and the function continues in the Receiver Module.

Applications:

- Human activities-walking, running, dancing etc.

- In constructional work

- Vehicle collision

- Navigation

- In electronics such as mobile phones and tablets.

\section{CONTROL STRATEGIES}

The project is based on microcontroller. This along with accelerometer forms the base for controlling the whole project. The microcontrollers, one each on transmitter module and receiver module, are programmed according to our need of operation. The operating signal is detected by the accelerometer. The accelerometer reads the XY co-ordinates made by our hand and sends it to the microcontroller on the transmitter module. This has the following functions: 


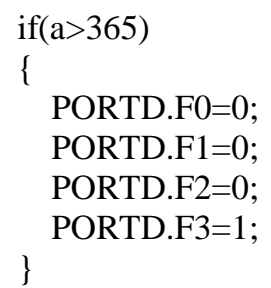

This function is for implementing back function. If the hand is rotated above $365 \mathrm{degs}$ in the $\mathrm{X}$ direction,

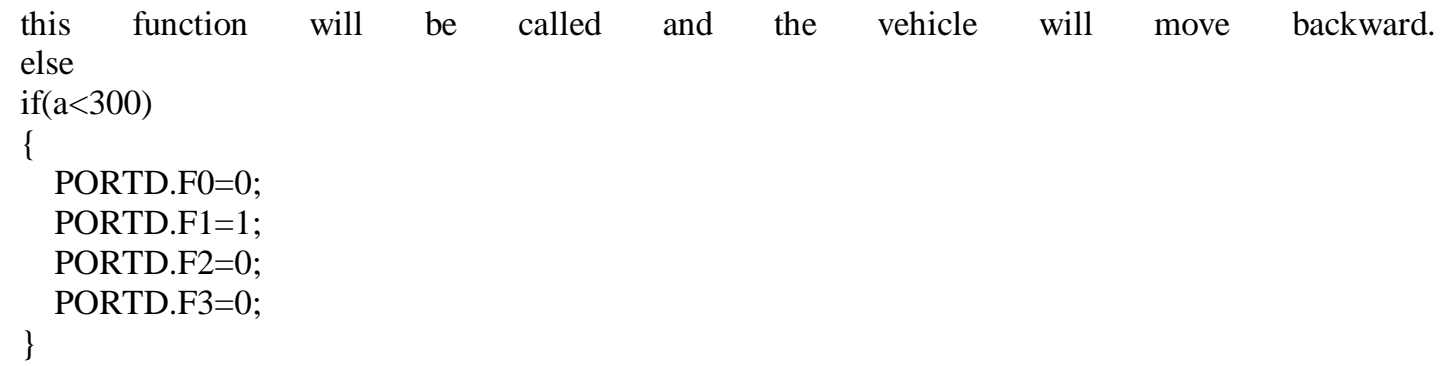

This function is for implementing front function. If the hand is rotated below 300degs in the $\mathrm{X}$ direction,

this function will be called and the vehicle will move forward.

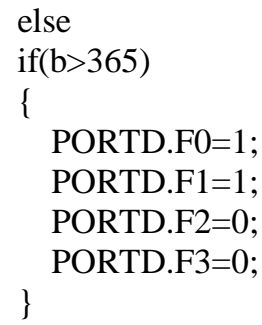

This function is for implementing left function. If the hand is rotated above $365 \mathrm{degs}$ in the $\mathrm{Y}$ direction,

this function will be called and the vehicle will turn to left.

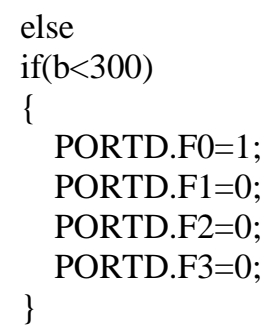

This function is for implementing right function. If the hand is rotated below 300degs in the Y direction, this function will be called and the vehicle will turn to right.

If none of the above conditions are satisfied then a stop function is called in which the vehicle does not

move.

The microcontroller on the receiver module receives data from the decoder which itself receives from the RF Receiver and RF Transmitter system. The following functions are given to it:

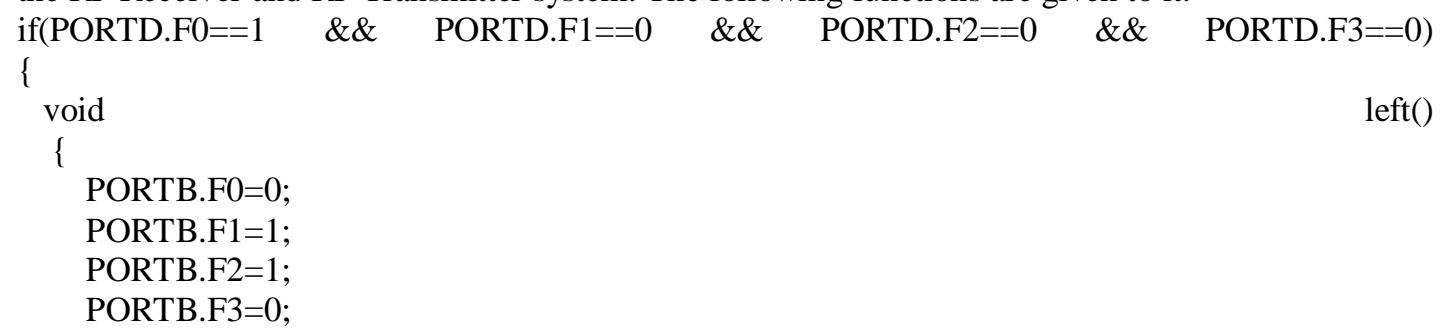


\}

\}

If the above stated if condition is satisfied i.e if in port D, pin 0 is set to 1 , pin 1 , pin2 and pin 3 is set to 0 , then the function left is executed. This makes the dc motors with both the wheels move anticlockwise the vehicle turns to left.

if(PORTD.F0 $=1 \quad \& \& \quad$ PORTD.F1 $==0 \quad \& \& \quad$ PORTD.F2 $==0 \quad \& \& \quad$ PORTD.F3==0)
$\quad$ void

\{

PORTB.F0 $=1$;

PORTB. $F 1=0$;

PORTB.F2=0;

PORTB.F3=1;

\}

If the above stated if condition is satisfied i.e if in port $\mathrm{D}$, pin 0 and pin 1 is set to 1 , pin 2 and pin 3 is set to 0 , then the function right is executed. This makes the dc motors with both the wheels move clockwise the vehicle turns to right.

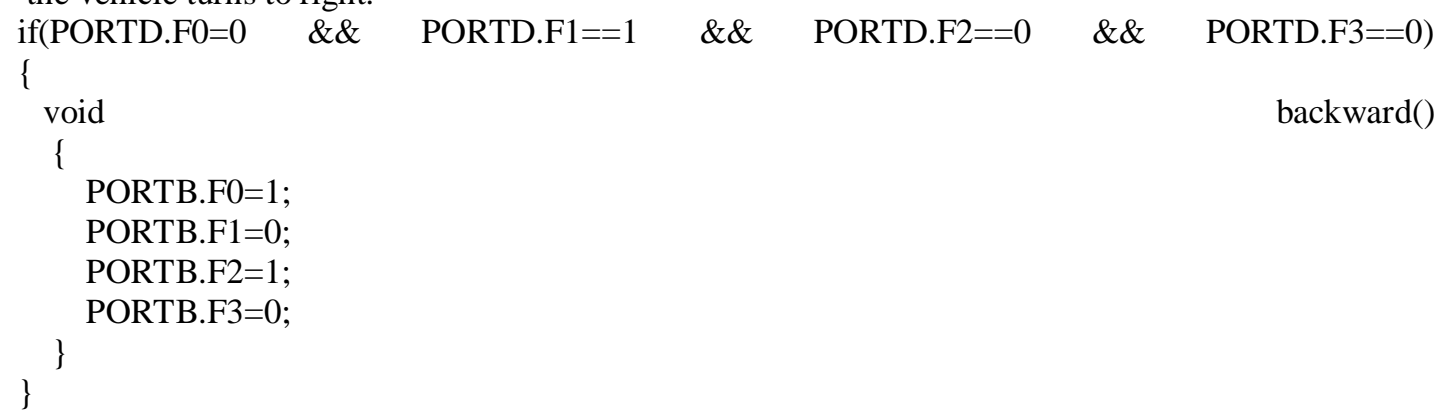

If the above stated if condition is satisfied i.e if in port $\mathrm{D}$, pin 1 is set to 1 , pin 0 , pin 2 and pin 3 is set to 0 , then the function forward is executed. This makes the dc motor with left wheel move clockwise and the right one move anticlockwise and thus the vehicle moves backward.

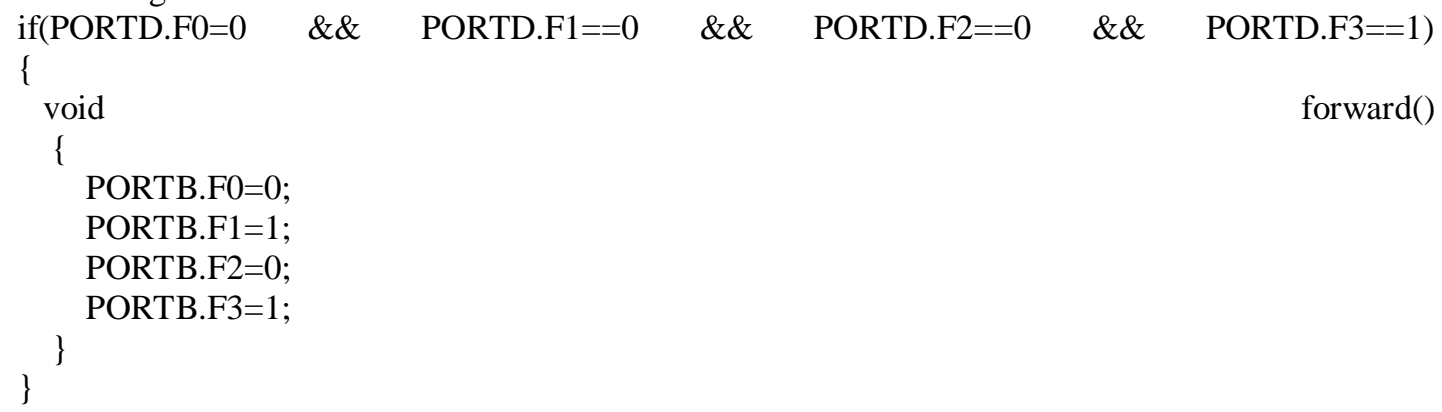

If the above stated if condition is satisfied i.e if in port $D$, pin 1 is set to 1 , pin 0 , pin 2 and pin 3 is set to 0 , then the function backward is executed. This makes the dc motor with left wheel move anticlockwise and the one with right wheel move clockwise and thus the vehicle moves straight to front. If none of the above conditions are fulfilled then the vehicle is at rest. A stop function is also implemented to determine any break in emergency.

\section{RESULTS AND DISCUSSIONS}

Radio Frequency transmission is used in the project which makes it suitable for a wider range of use. RF works even if there is any obstruction between the vehicle and the control and its frequency is 433 MHz. The transmission occurs between 8-10 kbps. The speed of the motor is roughly around $110 \mathrm{rpm}$. The PIC microcontroller proves to be best suited for the project. Besides all the advantages, this project module restricts fine movements when the work is done on bigger projects. 


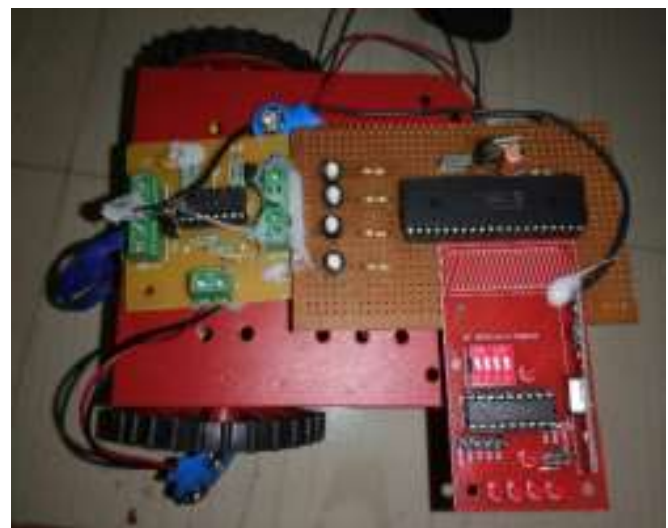

Figure 10. Transmitter module (Vehicle)

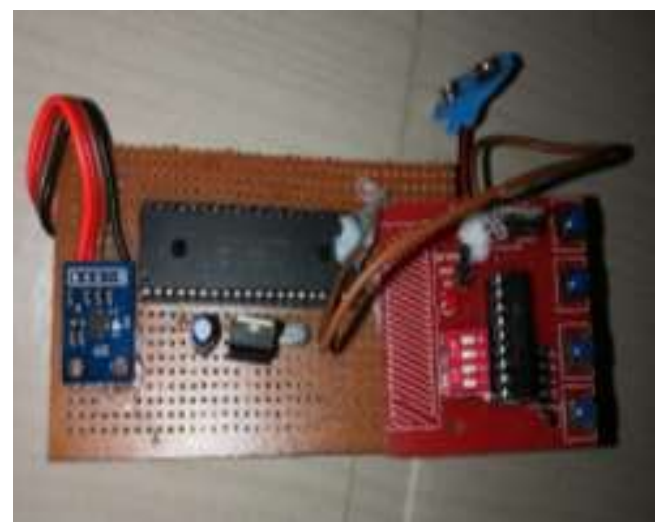

Figure 11. Receiver module (Glove)

\section{CONCLUSION}

The proposed paper on Gesture Recognition Vehicle stands true for use in small applications. For larger applications, use of devices accordingly is recommended. Although we may use it in lifts or vehicles with minimum load, heavy loads can be implemented with modifications in the same module. In future, we may apply IOT (Internet of Things) concept along with the proposed one to achieve better results.

\section{REFERENCES}

[1] P. D. Grant, M. W. Denhoff and R. R. Mansour, "A Comparison between RF MEMS Switches and Semiconductor Switches," International Conference on MEMS, NANO and Smart Systems (ICMENS'04), pp. 515-521, Banff, AB, Canada, 2004.

[2] G. M. Rebeiz and J. B. Muldavin, "RF MEMS switches and switch circuits," in IEEE Microwave Magazine, vol. 2, no. 4, pp. 59-71, Dec. 2001.

[3] J. J. Yao, "Micro Electro mecahnical RF Switch", United States Patent, Patent Assignee: Rockwell International Corporation,Patent, No.5578976, Nov.1996.

[4] D. Peroulis, S. Pacheco, K. Sarabandi and P. B. Katehi, "MEMS devices for high isolation switching and tunable filtering," IEEE MTT-S International Microwave Symposium Digest (Cat. No.00CH37017), vol. 2, pp. 1217-1220, Boston, MA, USA, 2000.

[5] T. Baudel, M. Baudouin-Lafon, "Charade: remote control of objects using free-hand gestures," Comm. ACM, vol. 36 no. 7 , pp. $28-35,1993$.

[6] D. J. Sturman and D. Zeltzer, "A survey of glove-based input," in IEEE Computer Graphics and Applications, vol. 14, no. 1, pp. 30-39, Jan. 1994.

[7] T. Takahashi, F. Kishino, "A hand gesture recognition method and its application," Systems and Computers in Japan vol. 23, no. 3, pp, 38-48, 1992.

[8] A.F. Bobick, A.D. Wilson, "A state-based technique for the summarization and recognition of gesture," Proceedings fifth international conference on computer vision, pp. 382-388, 1995.

[9] L. Bretzner, I. Laptev and T. Lindeberg, "Hand gesture recognition using multi-scale colour features, hierarchical models and particle filtering," Proceedings of Fifth IEEE International Conference on Automatic Face Gesture Recognition, Washington, DC, USA, 2002, pp. 423-428.

[10] Nilsson, N. J. "Principles of Artificial Intelligence," Tioga Press, 2005.

[11] Integrated person tracking and activity recognition with plan-view templates from a single stereo camera. IEEE Computer Society Conference on Computer Vision and Pattern Recognition, 2009.

[12] Collaborative Multi-Robot Exploration. In Proc. IEEE International Conference on Robotics and Automation. pp. 476- 481. IEEE International Conference on Robotics and Automation, San Francisco. USA. California 2010.

[13] Mohamed Naufal Bin Omar, "Pick and Place Robotic Arm Controlled By Computer," Faculty of Manufacturing Engineering, April 2007.

[14] K. Balasubramanian, R. Arunkumar, J. Jayachandran, V. Jayapal, B. A. Chundatt, and J. D. Freeman, "Object recognition and obstacle avoidance robot," in Chinese Control and Decision Conference. IEEE, pp. 3002-3006, 2009.

[15] E. M. Wong, "A phone-based remote controller for home and office automation," IEEE Transactions on Consumer Electronics, vol. 40, no. 1, pp. 28-34, 1994.

[16] I. Coskun and H. Ardam, "A remote controller for home and office appliances by telephone," IEEE Transactions on Consumer Electronics, vol. 44, no. 4, pp. 1291-1297, 1998.

[17] G. Ciardo and C. Lindemann, "Analysis of deterministic and stochastic Petri nets," in Proc. IEEE 5th Int. Workshop, pp. 160-169, Oct. 1993. 
[18] M. A. Marsan and G. Chiola, "On Petri nets with deterministic and exponentially distributed firing times," in Advances in Petri Nets, pp. 146-161, Berlin, Germany: Springer-Verlag, 1987.

[19] A. Zimmermann, M. Knoke, A. Huck, and G. Hommel, "Towards version 4.0 of TimeNET," in Proc. 13th GI/ITG Conf. Meas., Modeling Eval. Comput. Commun. Syst., pp. 477-480, 2006.

[20] H. A. P. Blom, J. Krystul, G. J. Bakker, M. B. Klompstra, and B. Klein Obbink, "Free flight collision risk estimation by sequential Monte Carlo simulation," in Stochastic Hybrid Systems; Recent Developments and Research Trends, C. G. Cassandras and J. Lygeros, Eds. New York: Taylor \& Francis, 2007.

[21] M. Ghazel, "Using stochastic Petri nets for level-crossing collision risk assessment," IEEE Trans. Intell. Transp. Syst., vol. 10, no. 4, pp. 668-677, 2009.

[22] George Fernandez.S, K.Vijayakumar and R.Palanisamy, "GPS \& GSM Based Accident Detection and Auto Intimation," Indonesian Journal of Electrical Engineering and Computer Science (IJEECS), vol. 11 , no. $1,2018$.

[23] T. Gomi, K., Ide and H. Matsuo, "The development of a fully autonomous ground vehicle (FAGV)," Proceedings of the Intelligent Vehicles '94 Symposium, pp. 62-67, Paris, France, 1994.

[24] M. Cellini, R. Mati, L. Pollini and M. Innocenti, "Obstacle Avoidance for Autonomous Ground Vehicles in Outdoor Environments," IEEE Intelligent Vehicles Symposium, pp. 258-263, Istanbul, 2007.

[25] Reinhold Behringer, William Travis, Rob Daily, David Bevly, WilfriedKubinger, Wolfgang Herzner and Victor Fehlberg, "RASCAL-An Autonomous Ground Vehicle for Desert Driving in the DARPA Grand Challenge 2005," IEEE Conference on Intelligent Transportation Systems, pp. 644-649, 2005.

[26] A. Ko and H. Y. K. Lau, "Robot Assisted Emergency Search and Rescue System With a Wireless Sensor Network," International Journal of Advanced Science and Technology, vol. 3, pp. 69-78, 2009.

[27] Harmon S., "The Ground Surveillance Robot (GSR): An Autonomous Vehicle Designed to Transit Unknown Terrain,” IEEE Journal of Robotics and Automation, vol. 3, no. 3 pp. 266-279, 1987. 